\title{
EDITORIAL
}

\section{The epidemiologist and the pandemic}

\section{Puneet Misra}

Professor, Center for Community Medicine, All India Institute of Medical Sciences, New Delhi 110029, India

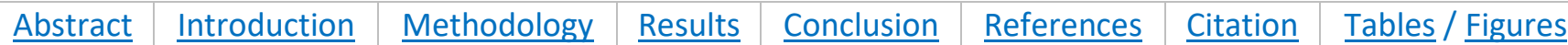

\section{Corresponding Author}

Dr. Puneet Misra, Professor, Center for Community Medicine, All India Institute of Medical

Sciences, New Delhi 110029, India

E Mail ID: dr.puneetmisra@aiims.gov.in

\section{Citation}

Misra P. The epidemiologist and the pandemic. Indian J Comm Health. 2020;32(2-Special Issue):184-187.

Source of Funding: Nil Conflict of Interest: None declared

\section{Article Cycle}

Received: 13/04/2020; Revision: 15/04/2020; Accepted: 16/04/2020; Published: 20/04/2020

This work is licensed under a Creative Commons Attribution 4.0 International License.

\section{Abstract}

Like Cholera outbreak of London in 1854, Spanish flu in 1920 or many other pandemic and epidemics thereafter including the current pandemic of COVID 19, it has again reminded to the world about the role of epidemiologist and epidemiological principles in controlling any such event where there is no cure available and thus saving the mankind. It points towards the urgent need of strengthening our public health infrastructure. This should be started with recruitment of competent epidemiologists on priority at district, state and country level. We should make use of full potential of members of IPHA and IAPSM mainly by providing data and help in policy making. This would help in developing capacity for timely action in best interest of our population for any threat of outbreak, epidemic or pandemic in current scenario and in future.

\section{Keywords}

COVID-19; Epidemiologist; Pandemic; Corona

COVID 19 pandemic is the most talked about illnesses presently due to its huge impact on all the aspects of human life and its existence. Whole mankind is worried and emotions are almost same all over world. There is panic, helplessness, fear, anxiety and hope, prayers for activities. And all this due to a tiny virus despite us thinking of ourselves as well advanced in modern medicine and science. So did it change the world?

Yes, novel corona virus has changed the world but is it because of the pandemic itself or because of how all of us have responded to it? Who are supposed to be first responders at the time of epidemics and pandemics?

When I ask these questions to myself, it reminds me of many epidemics and pandemics about which I read in medical history books, the most striking story, is the story of John Snow. This story is about the epidemic of Cholera in UK long back in 1854. It fascinated me from the days of my medical school because at that time he controlled Cholera epidemic without knowledge of bacteria, or the mode of spread of disease or any antibiotic or treatment. His contributions in containing an outbreak of cholera in the vicinity of Golden Square, central London, in the late summer of 1854 , and the subsequent removal of the handle from the Broad Street pump, have become an enduring feature of the folklore of public health and epidemiology (1). Even after so many years when novel corona virus pandemic hit the world in 21st century it reminds me again the role of epidemiologist to fight an unknown disease to win it completely through the tools they have. A story often comes to my thoughts whenever I think of those basic epidemiological tools. It is unique specially in the quest and thinking of human being to ask and answer 6 questions i.e. What, Why, When, How, Where and Who which I quote from a children's book by Rudyard Kipling in his "Just So 
Stories" (1902), in which a poem, accompanying the tale of "The Elephant's Child", opens with:

I keep six honest serving-men

(They taught me all I knew);

Their names are What and Why and When

And How and Where and Who.

These questions are basically are the basis of any epidemiological study and constitutes the basics of epidemiological tools and epidemiology, which is the study of disease in populations (2). In other words, Epidemiology is the study of how often diseases occur in different groups of people and why. Epidemiological information is used to plan and evaluate strategies to prevent illness and as a guide to the management of patients in whom disease has already developed. (3) Certain key activities performed by epidemiologists to support outbreak response and control includes: Calculating epidemiological parameters: R0, incubation rates, serial intervals, secondary attack rates; establishing standardized case definitions for suspect, probable and confirmed cases; creating standardized alert, case investigation and clinical record forms (4). In the current scenario when things are still not very clear about how virus evolved, all the modes of transmission, kind of pathogenesis it leads too along with progression pathways, prevention is the only cure. Understanding transmissibility remains crucial for predicting the course of the epidemic and the likelihood of sustained transmission. Understanding from previous outbreaks like MERS and pandemic influenza has shown that as an epidemic evolves, we face an urgent need to expand public health activities in order to explain the epidemiology of the novel agent and characterize its possible impact (5). During such events epidemiologic investigations, surveillance and containment are crucial activities for an effective public health response for right and quick decisions from the knowledge which is available at that point (6). These epidemiologic and surveillance activities promptly enable us to choose the most efficient ways of controlling the epidemic and help us avoid interventions that may be unnecessarily costly or unduly restrictive of normal activity (5). It is the epidemiological knowledge which is taking a lead until a vaccine or cure is available to fight an illness which is unknown not only to civilizations but to human immune system as well.
One of Ex Principle Advisor of Public Health to the Govt of India very well described how should these pandemics be controlled and it depicts main role of public health professionals based on epidemiological information. In his words "The strategy and control of such pandemic should vary from country to country depending on their capacity, socio economic condition, demographic structure, geographical location, healthcare infrastructure, public health organization, and infrastructure" (7).

Even before the declaration of the Pandemic by $\mathrm{WHO}$, based on these principles and evolving epidemiological knowledge, India was among first country to start screening of passengers at airports in January 2020. Early immigration control from China prevented the seeding of the COVID 19 infections in India. Concurrent implementation of Screening, Isolation, and Quarantining of infected and suspect cases as well as other surveillance and containment measures reduced the rate of spread. Unlike other countries, strict surveillance measures especially Contact tracing using various technologies and use of "Enforced Social Distancing" India reasonably contained rapid progress of the infection and slowed down the spread by lockdown. Looking at the steps taken by Govt of India so far looks very timely and important public health steps. All these actions seem to have not only delayed the epidemic and flattened the curve to get time for preparedness but to also reduce the absolute number of cases. Recently in a press briefing it was quoted by Joint Secretary (Health) that if these steps would have not been taken the count would have been more then 200,000 by this time instead of around 7000 cases. These steps seem to be in line with the report of the WHO- China Joint Mission on Corona Virus 2019 (1624 February) (8) which endorses "the efficacy and effectiveness of anchoring COVID19 readiness and response plan in a thorough assessment of local risks and of utilizing a differentiated risk- based containment strategy to manage a outbreak in areas with no cases vs. clusters of cases vs. community level transmission."

Planning and preparedness efforts for COVID-19 pandemic are widespread and ongoing, on a scale likely not imagined in 1918 at the time of worst pandemic of 20th century. Before vaccine against the specific emerging pandemic virus strain is available, non-pharmaceutical interventions proposed by public health professionals can offer strategies for persons and communities to help slow 
spread of the virus (9). Preventive strategies have seen to be effective in countries that imposed control measures at an early stage to contain the spread among communities and nations (10). Public health interventions to combat the onslaught of the spread of a Pandemic should be based on the basis of the country specific epidemiological need compatible with the health policy, health care delivery system and other governance. However, despite our efforts, gaps remain in response readiness to severe pandemic situations. Beyond this pandemic we must continue working towards sustained preparedness against future emergent infectious diseases and unforeseen pandemics.

What roles are community medicine department taking? There is huge manpower and expertise in all the states of the country in form of Community Medicine experts, who can be utilized for containment plan, district and state level policies to control epidemic, modelling and communication activities to make people, policy makers and other stake holders aware.

Complete lockdown of a nation is one of the boldest step in the history of public health intervention, for preventing an emerging pandemic. It has been done in many countries to protect population from the clutches of an impending pestilence. This bold step must have been taken on the basis of a factual epidemiological data and sound tenets of public health practice provided by the National health experts of the country and research organization like ICMR. However, some critics have warned on the impact of the enforced social distancing on the population and on nations' economy. There is a reservation among many epidemiologists about epidemiological basis of this decision making. This reservation might be because of non-availability and sharing of data with epidemiological researchers in different professional organizations and academic institutions at large. This kind of apprehension and reservations might not be good for pandemic control measures and building bottom-up consensus in India. Plan should be made to share data with professional organizations and academicians for scientific data analysis to augment the capacity of government in wise decision making, which should be based on inputs of real experts in epidemiology, rather than so called TV experts of various disciplines explaining epidemiology in terms of their own propagated theories thus making people more confused. It emphasizes one more role of public health professional, which need to be taken by public health experts to share credible information so as to make people aware and thereby reduce panic in this era of lot of false information and myths being promoted on social media. Though local government (11) and WHO (12) are playing their part but still the epidemiologist should come up with robust data and evidences to burst the myths. Professional organizations like IAPSM and IPHA though are playing their part but this is the time that government should use full potential of epidemiologists of these organizations on war scale to contain this pandemic and to utilize this opportunity to scale up public health infrastructure in the country. It feels very disheartening that at the time of this pandemic public health infrastructure across the country is in bad shape where many states do not have even state level epidemiologists (13). Government should take timely measures to strengthen epidemiological services along with strengthening of public health care infrastructure of the country to fight such challenges now and in future.

'Though one size does not fit all but the epidemiologist fits all the pandemics'

\section{References}

1. Brody H, Rip MR, Vinten-Johansen $P$, Paneth $N$, Rachman S. Map-making and myth-making in Broad Street: the London cholera epidemic, 1854. Lancet Lond Engl. 2000 Jul 1;356(9223):64-8.

2. Bartlett PC, Judge LJ. The role of epidemiology in public health. Rev Sci Tech Int Off Epizoot. 1997 Aug;16(2):331-6.

3. Chapter 1. What is epidemiology? | The BMJ [Internet]. [cited $2020 \mathrm{Apr}$ 17]. Available from: https://www.bmj.com/about-bmj/resourcesreaders/publications/epidemiology-uninitiated/1what-epidemiology accessed on 12/04/2020

4. FutureLearn. Outbreak response: Epidemiologist [Internet]. FutureLearn. [cited 2020 Apr 17]. Available from:

https://www.futurelearn.com/courses/diseaseoutbreaks/0/steps/62648 accessed on 12/04/2020

5. Lipsitch $M$, Swerdlow DL, Finelli L. Defining the Epidemiology of Covid-19 - Studies Needed. N Engl J Med. 2020 Mar 26;382(13):1194-6.

6. Enanoria WT, Crawley AW, Tseng W, Furnish J, Balido J, Aragón TJ. The epidemiology and surveillance response to pandemic influenza $A$ (H1N1) among local health departments in the San Francisco Bay Area. BMC Public Health. 2013 Mar 27;13(1):276. 
7. Dharmshaktu DNS. The Lessons Learned from Current ongoing Pandemic Public Health Crisis of COVID 19 and its Management in India from Various Different Angles, Perspectives and way forward. Epidemiol Int E-ISSN 2455-7048. 2020 Mar 19;5(1):1-4.

8. Ma Y, Zhao Y, Liu J, He X, Wang B, Fu S, et al. Effects of temperature variation and humidity on the death of COVID-19 in Wuhan, China. Sci Total Environ. 2020 Jul 1;724:138226.

9. Qualls N, Levitt A, Kanade N, Wright-Jegede N, Dopson S, Biggerstaff $M$, et al. Community Mitigation Guidelines to Prevent Pandemic Influenza - United States, 2017. MMWR Recomm Rep Morb Mortal Wkly Rep Recomm Rep. 2017 Apr 21;66(1):1-34.

10. Deming ME, Chen WH. COVID-19 and Lessons to be Learned from Prior Coronavirus Outbreaks. Ann Am
Thorac Soc [Internet]. 2020 Apr 8 [cited 2020 Apr 17]; Available from: https://www.atsjournals.org/doi/abs/10.1513/Annal sATS.202002-149PS accessed on 12/04/2020

11. IndiaFightsCorona COVID-19 | MyGov.in [Internet]. [cited 2020 Apr 17]. Available from: https://www.mygov.in/covid-19/ accessed on $12 / 04 / 2020$

12. Myth busters [Internet]. [cited 2020 Apr 17]. Available from: https://www.who.int/emergencies/diseases/novelcoronavirus-2019/advice-for-public/myth-busters accessed on 12/04/2020

13. D.O. No.7(23)/2020-NMH-I, dated 7th April, 2020 issued by secretary health, Govt of India. 